Published in Dirk Geeraerts, Gitte Kristiansen, and Yves Piersman (2010) Advances in Cognitive Sociolinguistics. Berlin, New York, Mouton de Gruyter.

Awesome insights into semantic variation ${ }^{1}$ [this a pre-final version of the manuscript]

\title{
Justyna Robinson
}

\section{Abstract}

This paper demonstrates benefits of employing the Cognitive Sociolinguistic approach in the investigation of lexical polysemy. The discussion is based on the usage-based analysis of the adjective awesome in a speech community. The results indicate that polysemy is far from being a stable phenomenon both at the conceptual level as well as at the sociolinguistic level. This work also suggests that combining cognitive and sociolinguistic analytical methods provides helpful insights into flexibility of a polysemous category.

Key words: semantic variation, semantic change, awesome, polysemy, apparent time

\section{Introduction}

The need for a socio-cognitive orientation in linguistic research has been recently advocated within Cognitive Linguistics (see Geeraerts 2005, Kristiansen and Dirven 2008). It is argued that both of the disciplines - Cognitive Linguistics and Sociolinguistics - share common grounds. With regards to the subject matter, both are interested in learning about motivations for speakers' linguistic choices. From the point of view of methodologies employed, both take a usage-based, empirical approach to the analysis of language data.

This chapter constitutes a contribution to the discussion of the validity of Cognitive Sociolinguistics in language research, with a special focus on the semasiological 
variation. I demonstrate that employing the socio-cognitive approach provides further insights into the flexibility of a polysemous category, especially in the context of diachronic changes of meaning.

The discussion revolves around the analysis of semantic variation of the adjective awesome. The analysis on the conceptual level is further complemented with the information on speakers' age, gender, and socio-economic status. The results are explored within appropriate cognitive and variationist paradigms.

\subsection{Review}

Sociolinguistics assumes that language variability mirrors social structure (Weinreich, Labov, and Herzog 1968). Seminal works in that area include Labov's Martha's Vineyard (1963) and New York studies $(1966,1972)$ and Trudgill's Norwich study (1974). Since then, a structured variation has been regularly examined in the context of phonology and morpho-syntax (see summary in Chambers et al. 2002). However, conclusions concerning onomasiological and semasiological aspects of linguistic structure relatively rarely constitute a central theme of sociolinguistic research.

Although studies of lexis were carried out in the context of word geography (e.g. Orton et al. 1962, Peters 1988, Upton and Widdowson 1999) and borrowings (Poplack et al. 1988), onomasiological variation and change in the "Labovian" sense has only recently been explored (Boberg 2004). Interests in socio-semasiology also surface in recent studies. Successful attempts to investigate meaning variation were carried out within functional paradigms (Hasan 1989, 1992, 2009) or discourse analysis frameworks (Cheshire 2007, Macaulay 2005, 2006, Stenström 2000, Tagliamonte and D'Arcy, 2004, Wong 2002, 2008). Their findings indicate that meaning construction relates to sociodemographic dimensions and that semantic change can be motivated by speakers' desire to index different stances of their identity. These studies suggest that further exploration of semantic variation is worthwhile.

Cognitive Linguistics has always recognised meaning as the most important aspect of 
linguistic structure (Geeraerts and Cuyckens 2007:14). Cognitive Linguistics considers semantic structure to be flexibly reflecting speakers' perceptions and adapting to their interaction with a physical and cultural reality. In this context, one would expect the variation of meaning to be regularly on the agenda of cognitive research. Indeed, lexical meaning variation has been studied within this framework, especially in the context of corpus research (e.g. Gries 2006, Divjak 2006, Gries and Divjak 2009, Beeching 2005). However, relating lexical variation to external sociolinguistic factors has been approached rather rarely. The seminal work in this area is Geeraerts et al.'s (1994) study of onomasiological variation in the context of dialect development. As far as semasiological variation is concerned, findings also indicate that the use of different concepts can be explained by a variety of interacting factors, dialect being one of the most significant ones (e.g. Glynn et al. this volume).

From the theoretical perspective, both Sociolinguistics and Cognitive Linguistics agree on the variable nature of meaning, but in practice semantics has been explored to a different extent in both of these frameworks. In Sociolinguistics, there are few established methods that have been designed to deal with socio-semantics specifically. In Cognitive Semantics claims are often made at an abstract level and usage-based sociolinguistic approaches that consider individual speech differences are still relatively infrequent.

\section{Scope of research}

Sociolinguistics and Cognitive Linguistics have rarely been using one another's legacies. Thus, one might wonder if "a socio-cognitive enterprise" is at all worth pursuing in language research.

The present study addresses this question by looking into lexical polysemy. Two issues in particular are examined here:

- Can variationist sociolinguistics provide any insights into the conceptual structure of polysemy and cognitive processes involved in meaning variation and change?

○ How can Cognitive Semantics be of use for Sociolinguistics? 
In order to explore these issues, the usage of polysemous adjectives in present day English is analysed from a socio-cognitive perspective. In this work, I focus on cases study of the adjective awesome only. I investigate if different (socio-demographically) people have different conceptualisations of polysemous adjective awesome.

\section{Method}

In order to address the above-mentioned issues a method of investigation that would yield data suitable for socio-cognitive analysis is needed. From the traditional sociolinguistic perspective, we would need data from a representative sample of a speech community controlled for chosen socio-demographic factors, e.g. age, gender, or social class. A usage-based study would require a design that elicits actual choices of language users.

Data were elicited in one-to-one interviews with members of the same speech community. 72 English speakers from South Yorkshire ranging in age from 11 to 94 years old were interviewed. All of the volunteers were born locally and the majority of them lived in Sheffield. The sample of participants was equally representative of sociodemographic factors. Participants belong to four generations: up to 18, 19-30, 31-60, and over 60 years old. The divisions do not represent equal periods (in terms of a number of years), as they rather correspond to points of general lifestyle changes that are observable in the community. Each of age groups contains the same number of speakers (18) controlled for gender and socio-economic background.

In order to establish the usage of meanings (their type and frequency) of polysemous adjectives for individual speakers the following structure of questions was employed (here eliciting the usage of awesome):

Q: Who or what is awesome?

A: Grand Canyon.

Q: Why is the Grand Canyon - awesome?

A: Because it takes your breath away 
This elicitation procedure asks for a referent described by an adjective in question (Who or what is $[\mathrm{ADJ}]$ ?) and then asks for a clarification (Why is [REFERENT] [ADJ]?). This method is a suitable way of eliciting the natural usage of words as compared to asking direct questions about the meaning (i.e. 'What does awesome mean?'), which potentially elicit more conscious, formal, or standard variants. The answer to the question "Why is the Grand Canyon awesome?" provides participants' clarification on the sense in which an investigated polysemy was used. This information was particularly useful when the meaning of the adjective could not be identified on the basis of a referent only (e.g. "an awesome helper' turned out to be a 'horrible, nasty' helper, not a 'great' one).

Moreover, participants were instructed to answer each question with the first thing that comes to mind. By following a similar structure of questions with each participant, the usage of polysemous adjectives in the same context was elicited. As a consequence, comparable and thus quantifiable samples of the usage of individual meaning variants were obtained.

All together 15 adjectives were included in the interview: 8 adjectives with recently developed sense extensions, 7 controlling variables (polysemous adjectives without recently developed sense extensions and (broadly understood) monosemous adjectives).

In this paper, I report findings on one of the investigated variables, namely the adjective awesome. The structure of the polysemous category is first explored and then analysed in the context of cognitive and sociolinguistic paradigms.

\section{Case study: awesome}

The analysis of the adjective awesome is based on a corpus of interview data consisting of 188 observations (each participant provided on average three instances of usage of the investigated adjective). Responses involving the adjective awesome are manually categorised in terms of their usage into the following meaning groups. This is done 
mainly on the basis of the matching the referents and associated explanations of usage to senses listed in dictionaries. The following meaning groups are identified:

- Awesome 'great': referential readings denoted referents of everyday close importance to a speaker. Examples of use: family, friends, pets, weekends, shopping.

- Awesome 'impressive': understood as 'overwhelming, breathtaking'; usually referring to something or someone exceptional, outstanding feats, breath-taking perceptual experiences. Examples of use: God, mountains, nature, Niagara Falls, sportsmen, opera singers, the Notre Dame Cathedral.

- Awesome 'terrible': 'frightening, weird, dreadful'. Examples of use: operations, a nasty helper, ugly person, the war, bombings.

- Awesome "other": overlapping senses that could not be reliably assigned to any of above groups. Examples of use: "Natural events, such as volcanoes and earthquakes, because they are beyond your control". The existence of overlapping uses accounts for flexibility and nondiscreteness of a semantic category. Meaning is fuzzy at edges and this property allows for creating conceptual extensions and links between senses which in usage-based research should surface as overlapping readings. The awesome "other" category also includes "reported" uses of the adjective awesome, i.e. cases when a participant states that s/he knows of a meaning but denies using it.

\subsection{Cognitive semantics analysis of results}

The usage of awesome in the investigated speech community is illustrated in Figure 1. 


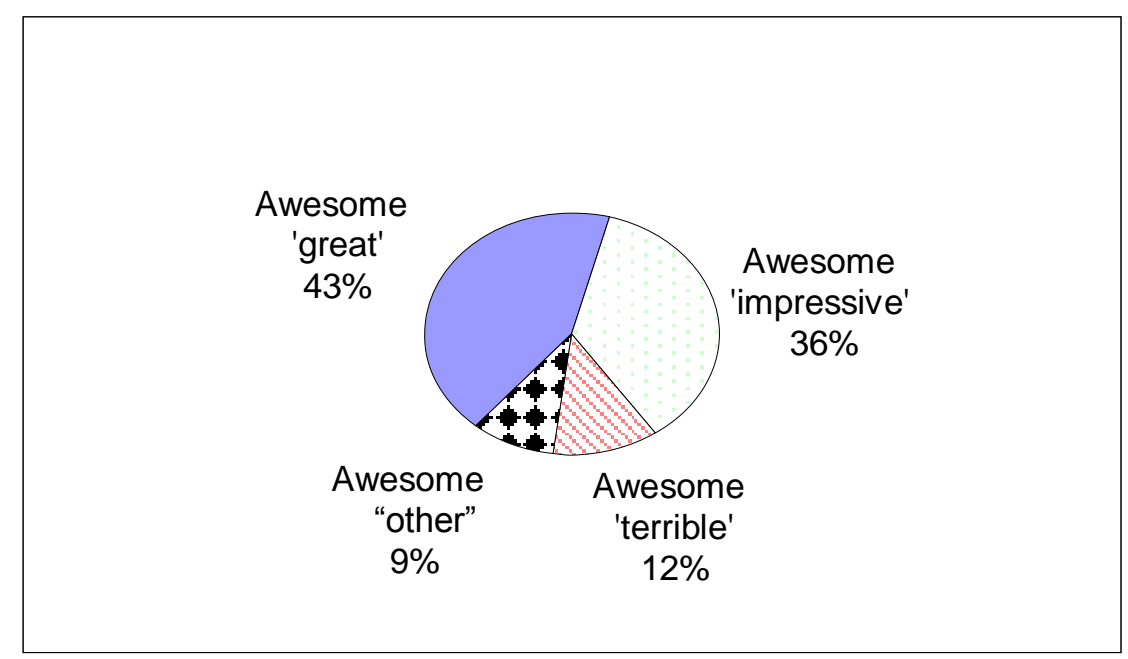

Figure 1. The usage of the adjective awesome.

The basic quantification of responses indicates that the most frequently used sense variant of this adjective is awesome 'great' (43\% of responses) followed by awesome 'impressive (36\% of responses). Awesome 'terrible', occurring in only $12 \%$ of responses, seems to be a far less salient sense of the polysemous category in the investigated speech community. The remaining 9\% of responses are ambiguous, overlapping, and reported cases grouped together in the category awesome "other".

Initial results confirm cognitive semantics assumptions about the nature of meaning. The adjective awesome is a complex polysemous category consisting of a cluster of overlapping senses, with some of them being more salient (such as awesome 'great') and others more peripheral (awesome 'terrible').

However, this purely conceptual analysis of responses is still not fully comprehensive. First, it is only satisfactory when one assumes the lack of dialect internal variation, that is, when we are happy with the statement that the language of a whole community is homogenous. Moreover, it is hard to read any patterns of change or tendencies in the development of the polysemous category (unless you take the most salient meaning as the "leading meaning"- but then how to interpret the chart considering dictionary evidence suggesting that awesome 'great' is merely peripheral, slang use of the adjective?).

In this context additional analytical steps are taken by including a sociolinguistic element to the present data. 


\subsection{Socio-cognitive semantics analysis: awesome}

In order to add a sociolinguistic facet to the analysis, participants' responses are analysed in the context of age, gender, and socio-economic status variables. Most of the discussion revolves around the category of age since a number of variationist studies have shown its significance in structuring and explaining linguistic variation (see e.g. Labov 1994, Eckert 1997, Romaine 1984). In addition, the metalinguistic comments of participants indicate that age might be an important factor in accounting for the observed semantic variation. The effect of gender and socio economic factors on the variation of the adjective awesome are discussed later on in the chapter.

The figure below illustrates the usage of the conceptual category awesome plotted as a function of age. Here the category "other" is split to represent individual reported and overlapping senses. 


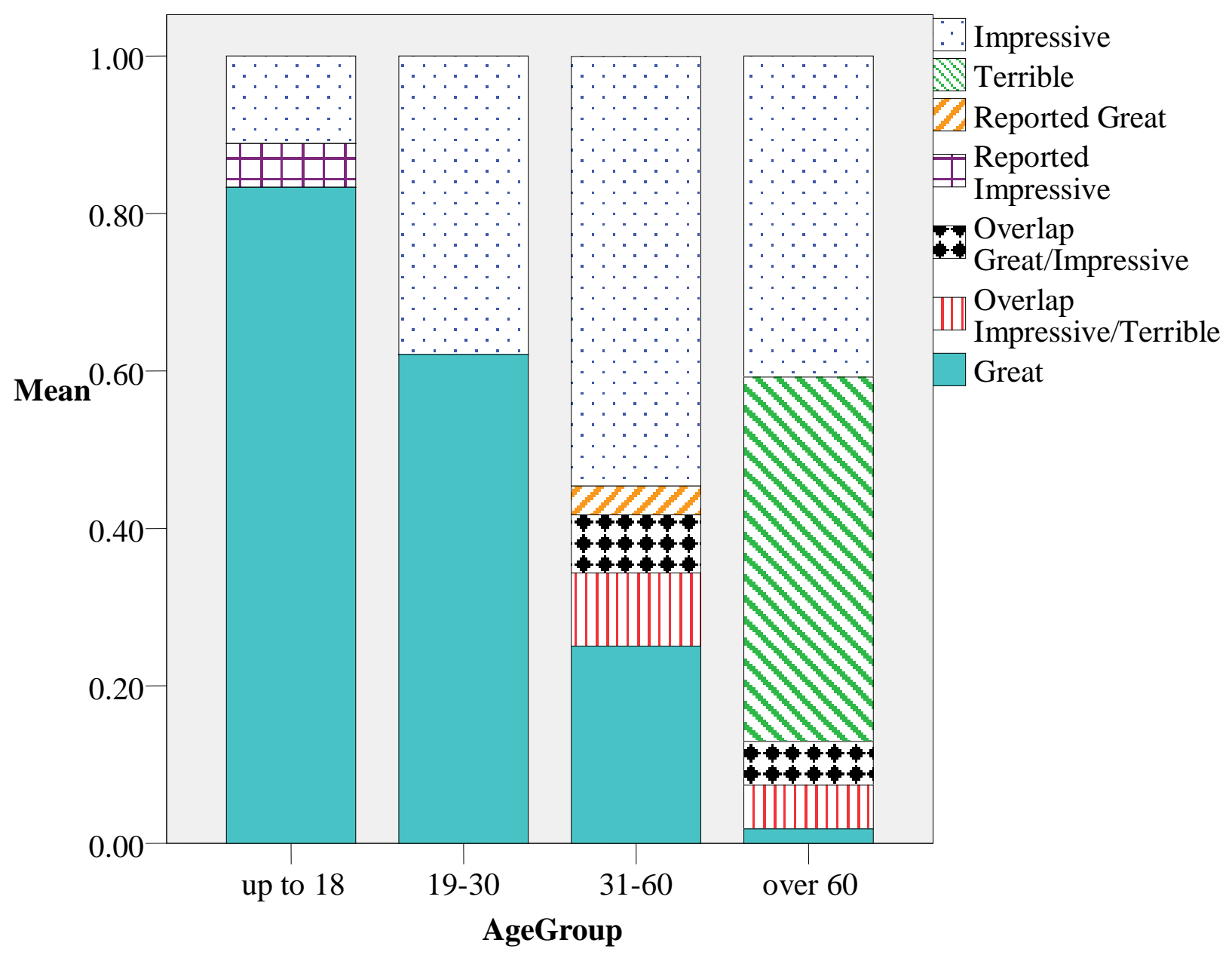

Figure 2. Age-related variation of the usage of the adjective awesome.

In comparison to the polysemy structure illustrated in Figure 1, Figure 2 presents a far more dynamic picture of the usage of the adjective awesome. Each bar on the chart indicates that the distribution of individual meanings is different for each age group. For instance, awesome 'great' is the most salient reading for speakers that are up to 18 year old, and the least frequent one for those over 60 years old.

This finding enhances our understanding of polysemy as a flexible phenomenon. One can see that the flexibility of the same polysemous category that was shown at community level (Figure 1) also emerges for individual age groups (Figure 2). However, the distribution of senses in Figure 2 varies to the one in Figure 1. The structure of each bar in Figure 2 indicates that individual conceptualisations of the adjective awesome are significantly different for different speakers within the same community ${ }^{2}$. 
This observation clearly supports a two-fold aspect of polysemous flexibility: (1) not every meaning is equally representative within a polysemous category; (2) not every meaning is equally salient for every speaker, even within the same speech community. The second remark is especially important in the context of the value of socio-cognitive research. It extends the findings of prototypical nature of meaning (Rosch 1975, Geeraerts 1989) by experimentally demonstrating the great extent to which the salient representations differ for individual speakers. Moreover, since each speaker has different experiences of the world and individually shaped understanding of a concept, the methods of investigation of experiential meaning need to go beyond abstract conceptual approaches, towards usage-based ones. This analysis shows that employing sociolinguistic methods of research helps to manage (qualify and quantify) the individuality of linguistic observations.

Another observation of the socio-cognitive analysis of the adjective awesome is that the core meaning for some speakers is completely different from that of the community as a whole. The most salient sense at community level (Figure 1) and for speakers up to 30 years old is awesome 'great'. But for speakers between 31 and 60 years old awesome 'impressive', and for those over 60 years old awesome 'terrible' are the most frequent uses of this polysemous adjective.

Thus, for half of participants the most salient meaning is different from what it is for a whole community. Why would this be the case? Especially, why would the core meaning of awesome be so different for speakers over 30 as compared to younger speakers? Of course, as was argued earlier, different speakers would have different individual conceptualisations. But how can we explain the fact that speakers within each generation share similar conceptualisations, which are yet significantly different between generations?

This question is addressed in the context of variationist paradigm, wherein we take a closer look at the significance of socio-demographic categories.

\subsubsection{Analysis of external factors in semantic variation}


By mapping the conceptual structure (Figure 1) onto the demographic one, a clear pattern emerges (Figure 2) - the use of particular senses is non-randomly related to the age of speakers. But to what extent does age actually explain the observed variation? Nonparametric statistics (Kruskal-Wallis tests) inform us only of the significant changes in mean usage between age groups.

Also, is speaker's age the only external factor that accounts for the use of senses of polysemous awesome? A number of studies indicate that gender and the socio-economic status of speakers may also account for linguistic variation (see review of relevant studies in Coates 2004, Eckert 1998, or Kerswill 2007). Could such factors also account for the semantic variation of awesome?

This section explores several socio-demographic variables in order to assess their significance in explaining observed variation of the polysemous awesome. Speakers' age, gender, education, occupation, and the place of residence are taken into consideration.

In order to address the above-mentioned issues, a multifactor statistical model needs to be employed, i.e. a model that considers several of external factors simultaneously and measures their effect on the use of different senses of awesome. In addition, the analysis has to be suitable for testing dependent variables which are binary (e.g. use vs. non-use of awesome 'great'). Finally, the appropriate statistical approach needs to allow us to check for nuisance variables which may be confounded. Socio-demographic factors may constitute such cases, e.g. education and occupation may be confounded, as people that are more educated are likely to have better jobs.

Logistic regression analysis is the appropriate procedure to fulfill these requirements. Logistic regression is a mathematical modelling approach that can be used to test hypotheses about the relationship of several independent variables to a dichotomous dependent variable (see Hosmer and Lemeshow 1989, Kleinbaum 1994, Tabachnick and Fidell 2001 for introduction to logistic regression). Usually it is used to predict a particular binary outcome (event or non-event) from a set of independents. For instance, 
you may want to use logistic modelling to assess if winning or losing a game of bridge can be predicted from the gender and years of experience of the players. Logistic regression also provides information on variance (the percentage to which an independent variable is explained by the dependent ones) and is used to determine the importance of independent variables. In this work, logistic regression is employed to assess the overall effect of socio-demographic factors on the use of individual senses of the adjective awesome. $^{3}$

The following independent variables are considered in the logistic model: age group, gender, education, National Statistics Socio-Economic Classification (NSEC) score, which is based on occupation, and a neighbourhood variable, which is based on property values in areas defined by a postcode of a participant's residence. For the summary of coding of independent variables see Table 1.

Seventy-two cases with missing values were included in the analysis; equal numbers of males and females (36), and equal amounts of members of each age group (18). The factors age group and gender were entered into the model. Further factors were eliminated using a backward stepwise method. This was done because the prime interest was in age and gender, the other variables were allowed to stay if they significantly altered the model as they were possible confounding variables. The final model is reported.

Table 1: Socio-demographic variables (independent variables) used in logistic regression analyses to investigate their association with the use of different senses of the adjective awesome (dependent variables).

\begin{tabular}{llllll}
\hline $\begin{array}{l}\text { Independent } \\
\text { Variables }\end{array}$ & Coded as & & Categories \\
\hline Age group & $(1,2,3$, & Up to 18 & $19-30$ & $31-60$ & Over 60 \\
& $4)$ & & & & \\
Gender & $(1,2)$ & Male & Female & & \\
NSEC & $(1,2,3)$ & Higher & Medium & Lower &
\end{tabular}




\begin{tabular}{llllll} 
Education & $\begin{array}{l}(1,2,3, \\
4,5)\end{array}$ & $\begin{array}{l}\text { Prior to the } \\
\text { age of } 16\end{array}$ & $\begin{array}{l}\text { Secondary } \\
\text { school }\end{array}$ & $\begin{array}{l}\text { College/ } \\
6^{\text {th }} \text { form }\end{array}$ & $\begin{array}{l}\text { University } \\
\text { Neighbourhood }\end{array}$ \\
$(1,2,3)$ & $\begin{array}{l}\text { Lower } \\
\text { property } \\
\text { prices }\end{array}$ & $\begin{array}{l}\text { Middle } \\
\text { property } \\
\text { prices }\end{array}$ & $\begin{array}{l}\text { Highest } \\
\text { property } \\
\text { prices }\end{array}$ & $\begin{array}{l}\text { a student } \\
\text { pricenty }\end{array}$ \\
\hline
\end{tabular}

\subsubsection{Awesome 'great'}

Logistic regression analysis is carried out to assess the overall effect of sociodemographic factors (independent variables) on the use of awesome 'great' (dependent variable).

The summary of results of the logistic regression analysis of the use of awesome 'great' is presented in Table 2. The final model reported includes variables which best account for the observed variation. Insignificant variables are excluded from the model. The table shows the coefficients of regression Beta (B), their standard errors, the Wald Chi-Square statistic, associated p-values, and odds ratio $(\operatorname{Exp}(B))$. The resultant fitted model indicates which independent variables are included in the final logistic model. It also informs us about significant changes in regression coefficients (B) between predictors. B determines the direction of the relationship between a given predictor and the dependent variable (the use of awesome 'great'). If B is positive, the odds of use of awesome 'great' are increased, when B is negative, the odds are decreased, B equalling 0 leaves the odds unchanged.

Table2. Logistic regression model for awesome 'great'.

\begin{tabular}{lrrrccr}
\hline & Beta & \multicolumn{1}{c}{ S.E. } & Wald & df & \multicolumn{1}{c}{ p } & $\operatorname{Exp(B)}$ \\
\hline AgeGroup & & & 20.018 & 3 & .000 & \\
AgeGroup(1) & .867 & .962 & .812 & 1 & .368 & 2.379 \\
AgeGroup(2) & 1.861 & .792 & 5.514 & 1 & .019 & 6.427 \\
${\text { AgeGroup }(3)^{\mathrm{c}}}^{\mathrm{c}}$ & 2.505 & 1.162 & 4.650 & 1 & .031 & 12.241 \\
Gender(1) & -1.260 & .689 & 3.343 & 1 & .068 & .284 \\
\hline
\end{tabular}




\begin{tabular}{lllllll}
\hline Constant & .023 & .376 & .004 & 1 & .950 & 1.024
\end{tabular}

${ }^{a}$ : indicator variable representing change between age group (19-30) in relation to age group (up to 18)

b: indicator variable representing change between age group (31-60) in relation to age group (19-30)

c: indicator variable representing change between age group (over 60) in relation to age group (31-60)

Main finding. According to the model, the age group contributes significantly to the model for the speakers' use of awesome 'great' ( $\mathrm{p}<.001)$.

Age group. The most significant differences of use exist between age groups (31-60) and (19-30) $(\mathrm{p}=.019, \mathrm{~B}=1.861)$, and also between age groups (over 60) and (31-60) $(\mathrm{p}=.031$, $\mathrm{B}=2.505$ ). These results indicate that the two youngest age groups speak most similarly to each other. The use of awesome 'great' significantly decreases for speakers of age (30 $60)$ and then for those over 60 years old.

Gender. The model also includes gender in the logistic model. Females are more likely to use awesome 'great' at marginally significant level $(\mathrm{p}=.068)$.

In the logistic regression analysis, the predictive and explanatory power of the fitted model needs to be assessed. In order to validate predicted probabilities, the c-statistics is used (see Peng et al. 2002:6). The c-statistics analyses the proportion of observed to initially predicted probabilities of occurrences of awesome 'great'. In the case of awesome 'great', the fitted model (one that includes socio-demographic variables) achieves a success rate of $84.7 \%$ which is an improvement over the intercept model, i.e. a model that does not include any of the socio- demographic variables to account for the observed variation, but includes a constant term only (52.8\%).

The explanatory power of the calculated model refers to how effectively it fits the actual data for estimating the outcome variable (Moss 2003: 925). This could be assessed by a number of "goodness-of-fit" measures. -2 Log Likelihood (-2LL) indicates the overall fit of the model. It reflects the significance of the unexplained variance in the model. Its lowering values indicate improvement of a model fit (increasing the likelihood of the observed results). R-square measurements (Cox and Snell, Nagelkerke tests) indicate how 
much variation the model actually explains. Sometimes these measures may yield different results (for further discussion see Field 2005: 239-240). The Hosmer and Lemeshow test is another measure that is considered by some researchers to be a more accurate measure for assessing goodness-of-fit of the model (Peng 2002:6). It tells you how closely the observed and predicted probabilities match and insignificant results of Hosmer and Lemeshow test signify a model that fits data well.

In the case of awesome 'great' lowering -2LL (59.742) and an insignificant HosmerLemeshow test indicate that the model fits the data well and is more adequate for explaining variation than models which do not consider socio-demographic factors. Rsquare measurements (Cox and Snell $=.425$, Nagelkerke $=.567$ ) indicate that the variation in the outcome variable is explained by logistic regression model moderately well.

Logistic regression analysis evidences that the use of awesome 'great' can be satisfactorily modelled from the age and gender of speakers, although age has a more significant overall effect on the use of the given variable than gender.

\subsubsection{Awesome 'impressive'}

Logistic regression analysis is carried out to assess the overall effect of sociodemographic factors (independent variables) on the use of awesome 'impressive' (dependent variable). The summary of results for logistic regression analysis of the use of awesome 'impressive' is presented in Table 3.

Table 3. Logistic regression model for awesome 'impressive'.

\begin{tabular}{lrrrrrr}
\hline & Beta & S.E. & Wald & df & \multicolumn{1}{c}{ p } & $\operatorname{Exp}(\mathrm{B})$ \\
\hline AgeGroup & & & 11.977 & 3 & .007 & \\
AgeGroup(1) & -2.572 & .928 & 7.679 & 1 & .006 & .076 \\
AgeGroup(2) & -.646 & .810 & .636 & 1 & .425 & .524 \\
AgeGroup(3) & 1.717 & .868 & 3.919 & 1 & .048 & 5.570 \\
\hline
\end{tabular}




\begin{tabular}{lrllllr}
\hline Gender(1) & 1.262 & .609 & 4.291 & 1 & .038 & 3.534 \\
Neighbourhood & 1.172 & .382 & 9.404 & 1 & .002 & 3.228 \\
Constant & -2.318 & .793 & 8.541 & 1 & .003 & .098
\end{tabular}

${ }^{\text {a }}$ : indicator variable representing change between age group (19-30) in relation to age group (up to 18)

: indicator variable representing change between age group (31-60) in relation to age group (19-30)

c: indicator variable representing change between age group (over 60) in relation to age group (31-60)

Main finding. According to the model, the age group and gender contribute significantly to the model for the speakers' use of awesome 'impressive'.

Age group. The most significant 'jumps' in B-coefficients exist between age groups (up to 18) and (19-30) $(\mathrm{p}=.006, \mathrm{~B}=-2.572)$ and age groups (over 60) and (31-60) $(\mathrm{p}=.048$, $\mathrm{B}=1.717$ ). These results indicate that speakers over 19 are most likely use of awesome 'impressive' as compared to younger participants.

Gender. The significant difference in Beta values exist between males and females' use of awesome 'impressive' ( $\mathrm{p}=.038, \mathrm{~B}=1.262$ ). Males are more likely to use this sense variant.

Neighbourhood. The fitted model also indicates that the inclusion of the neighbourhood significantly alters the model $(\mathrm{p}=.002)$. However, this variable may be confound: the older the person the richer the person.

An overall assessment and validation of the fitted model is discussed next. The cstatistics represent the proportion of observed to predicted probabilities of uses and nonuses of awesome 'impressive'. In the case of awesome 'impressive', the fitted model achieves a success rate of $79.2 \%$, which is an improvement over the entry model (model that includes age group and gender only) and intercept models (69.4\% and 50.0\% respectively).

The explanatory power of the fitted model is assessed by comparing it with the intercept and entry models. Increasing R-square measurements (Cox and Snell= .335, Nagelkerke $=.447$ ) suggest that the fitted model accounts for around $40 \%$ of variation which is a 
moderate outcome. Lowering (still not very low) -2LL (70.412), insignificant results on the Hosmer and Lemeshow test indicate that the final model fits the data well and reduces unexplained variation in comparison to the entry model and the intercept model.

Logistic regression analysis evidences that awesome 'impressive' can be satisfactorily modelled from participants' age, gender, and potentially area where they live (neighbourhood may be a confounding variable).

\subsubsection{Awesome 'terrible'}

Logistic regression analysis of awesome 'terrible' yields an unstable solution, so it is not possible to make predictions regarding the overall effect of external factors on the use of this meaning.

\subsubsection{Discussion of results}

\subsubsection{Age related variation of awesome}

Logistic regression modelling indicated that the overall effect of the age of participants on the use of awesome is significant. The use of awesome 'great' decreases with increasing age of participants; the use of awesome 'impressive' is lowest for the youngest generation. Although a stable logistic model could not be established for awesome 'terrible' we may at least fall back on results of non-parametric tests (Appendix 1), which show that this variable is used significantly more frequently by speakers over 60 years old $(\mathrm{p}<.001)$.

The significance of age in the observed variation may be interpreted within the apparent time construct as indicative of semantic change in progress.

The apparent time hypothesis indicates that linguistic differences among different age 
groups or generations reflect actual diachronic developments in language. In other words, linguistic trends observed in synchrony could actually indicate on-going changes.

A central thought of this approach refers to the uniformitarian principle, which asserts that:

\author{
"If there are relatively constant, day-to-day effects of social \\ interaction upon grammar and phonology, (...) these influences \\ continue to operate in the same way that they have in the past" \\ (Labov 1972: 275)
}

Labov's (1963) analysis of variation and change on Martha's Vineyard is the seminal work in this area. He argues that the rise in the use of centralised variants of (ay) and (aw) in apparent time reflects actual diachronic changes in the use of the features on Martha's Vineyard (Figure 3).

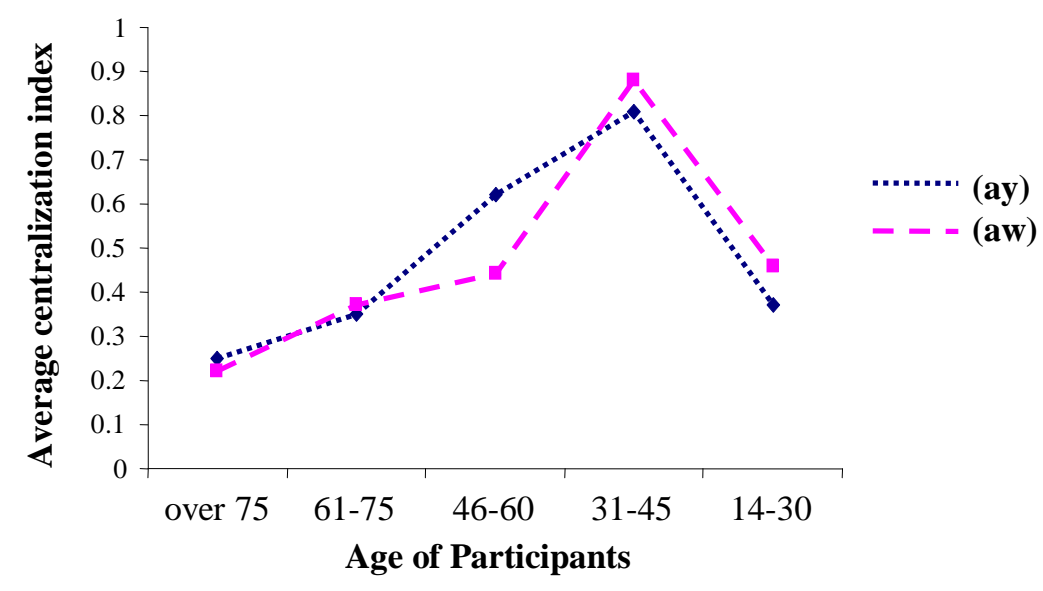

Figure 3. Centralisation index by age groups for (ay) and (aw) on Martha's Vineyard. Source: Labov (1963). 
The model confirmed predictions concerning past trends as evidenced in data collected for the Linguistic Atlas of New England (Kurath 1941) more than 20 years earlier (Labov 1963: 275-276). The real-time evidence (Pope 2002) corroborated that Labov's anticipated pattern of centralisation of (aw) and (ay) continued in the way that 1963 survey indicated. The apparent time construct has been shown to be a successful way of investigating language variation and change in different speech communities (see the summary of relevant studies in Bailey 2002, Sankoff 2006, or Tagliamonte and D'Arcy 2009).

Based on the apparent time construct, observed generational differences in the usage of different sense variants of the adjective awesome may be interpreted as semantic change in progress. One could argue that awesome 'great' is developing as the core meaning of the polysemous category. Awesome 'terrible' is likely to soon be considered archaic since it is only active for the oldest members of that speech community.

Available real time evidence confirms the apparent time prediction. For instance, the Oxford English Dictionary Online indicates that awesome 'awful, dreadful, terrible' was in use since the $16^{\text {th }}$ century, much earlier than awesome 'impressive' and 'great'. First quotations of awesome 'overwhelming, impressive, breath-taking' in the OED Online date back to the 1960s and awesome 'good, great' does not seem to be recorded in British English until the early 1980s, which is also confirmed by data from the LancasterOslo/Bergen Corpus of British English (1961), and the British National Corpus.

The present study only hypothesizes change in progress of the adjective awesome and the observed trends can only be verified in 40 - 50 years time. However, apparent time studies so far show that locating a gradient age distribution in a community under study virtually assures of having identified change, whether or not age grading is also involved (Sankoff 2006: 111).

\subsubsection{Effects of Gender and Neighbourhood}


The fitted models for polysemous awesome also includes gender and neighbourhood alongside the age group factor. The use of awesome 'great' can be modelled from the speech of females and the use of awesome 'impressive' can be modelled from the speech of males and from the type of neighbourhood (measured by property value) speakers live in.

Considering the historical information on the emergence of the senses, one may interpret these findings as follows: males use the more standard meaning (awesome 'impressive'), females lead the use (change) of the newer sense extension (awesome 'great'). Also, since the area speakers live in could be interpreted as one of indexes of a socio-economic status (Roberts 2001), one could suggest that middle classes would exhibit more standard usage as well. However, the interpretation of effects of neighbourhood variable should be cautious, since this variable may confound with age: the older you are the richer you become.

These results fit well with findings from other variationist studies (see summary in Kerswill 2006). Women, especially middle aged and located in the middle of socioeconomic continuum lead linguistic change. A more standardised speech is often characteristic of the upper classes.

\subsubsection{Polysemy: a dynamic picture}

In the context of the apparent time hypothesis it becomes apparent that Figure 2 does not only represent variation of polysemous readings, but a dynamic picture of semantic change in progress. One can already notice the potential benefits of employing a sociocognitive method; in other words benefits of mapping individual conceptualisations of a polysemous category onto a variationist context.

The fact that the change in progress was observed helps to shed light onto the differences between individual, generational, and community representations of the core meanings of 
awesome. The representation of awesome at community level (Figure 1) does not correspond to what is observed at generational level (Figure 2) because each generation actually represents a different stage in the diachronic development of this category. Speakers' conceptualisations relate socio-culturally to the language of a particular period, which to a large extent appears to be "frozen" in their age. For instance, older speakers are more likely to reflect the language of their generation which would basically involve forms that they learnt when they were younger and subsequent modifications. Similarly, younger generations reflect the language, which is an outcome of a usage "competition" between forms that they learn from parents, teachers and new forms they negotiate in their peer groups. These different conceptualisations emerge at the socio-cognitive level as a variation of uses non-randomly distributed across the age axis.

Another observation concerns the nature of semantic change itself. Fine-grained variationist investigation provides evidence for the existence of conceptual links between successive senses (cf. Geeraerts 1997, Nerlich and Clarke 1992). In the pattern of change derived from the apparent time construct (awesome 'terrible'> 'impressive'> 'great') awesome 'terrible' and awesome 'impressive' seem to be connected by an element of intensity of emotion, and awesome 'impressive' and awesome 'great' are similar in the context of positivity of emotion that exists between them. Conceptual links between senses can also be found in examples grouped in the category awesome "other". This category includes overlapping senses, which can (but do not have to) be first signals of a particular category being used in a novel way. What is interesting here is that the examples represent overlapping of senses that are diachronically successive (e.g. awesome 'terrible' and awesome 'impressive', but never awesome 'terrible' and awesome 'great'). Moreover, the overlapping readings do not occur where one would not expect them to occur. For example, overlap involving awesome 'terrible' (the oldest sense) does not occur in the speech of the youngest generation but in generations which use this sense (over 60) and in the neighbouring younger generation (31-60) (see Figure 2).

Socio-cognitive analysis also helps to shed light on the circumstances surrounding the emergence of new meanings. This approach permits us to identify speakers who are 
likely to be responsible for innovating and propagating novel uses of a word, but also those who most resist innovation. In the case of awesome, one can see that speakers of the age 31-60 are the first to use awesome 'great', and those over 60 are the last to still be using awesome 'terrible'. Logistic regression analysis showed that the innovative meaning can be modelled from the speech of women, and the more standard meaning can be modelled from the speech of men and potentially upper classes. These general observations open the door to a potentially far more insightful analysis of the circumstances in which a conceptual category successfully enters a social construct. One could analyse the positioning of innovators in the socio-economic structure of a given community and investigate social practices and networks they are a part of. As a consequence, such an approach could potentially get us a step closer to showing how a new meaning gets experientially grounded.

The socio-cognitive analysis of awesome indicates that fluctuations in the usage of a semantic category systematically relate the socio-demographic characteristics of a speech community. This observation positively contributes to the discussion on the validity of a socio-cognitive orientation in linguistic research.

\section{Summary and Conclusions}

This work explores and discusses the benefits of a socio-cognitive orientation in linguistic research by carrying out a usage-based investigation of the polysemous adjective awesome. Although the initial analysis revealed the complexity of the polysemous category, it was not until a socio-demographic facet was imposed onto our data where fine-grained aspects of polysemous flexibility emerged.

The first striking observation was to discover the multiplicity and complexity of conceptualisations at different levels of analysis of the speech community. The core meaning of the investigated polysemy varied significantly for individual speakers and individual generations even within the same, comparatively small speech community. 
Also, we have found that this "conceptual mess" can be better organised and interpreted within a variationist framework. A complex polysemy structure characteristic for each participant and each generation started forming a regular pattern when mapped on the demographic structure of a whole speech community. The apparent time hypothesis supported with adequate statistics indicated that this pattern, being a function of linguistic usage and the age of speakers, in fact indicates semantic change in progress. Thus, a socio-cognitive approach enabled us to trace polysemous flexibility step-by-step, or should we say, speaker-by-speaker, until seemingly "meaningless" individual variations actually showed real development of meaning in time.

This finding points to the importance of looking into individual speakers; and the way their conceptualisations and perceptions are grounded in the socio-demographic and cultural reality. Of course, this line of thinking is not novel for Cognitive Linguistics which has argued for the experiential nature of language for a considerable time. Unfortunately, there have been few studies that put this perspective into practice and analyse the language and environment of individual speakers (cf. Dąbrowska and Street 2006). One of the reasons for this situation might relate to the fact that Cognitive Linguistic methods of investigation are not well suited to tackle the social aspects of language and Variationist Sociolinguistics struggles to capture the complexity of meanings with the available tools. Therefore, combing sociolinguistic and cognitive approaches fills these gaps by potentially bringing beneficial solutions to language research at a methodological level.

Finally, this study also indicates the necessity of including external factors in exploring conceptual variation. The analysis of the adjective awesome shows that semasiological variation is not free but regularly structured in terms of the age, gender, and social class of speakers. This finding contributes to observations of other scholars who demonstrate that the entrenchment of conceptual categories can be explained in relation to external factors (e.g. Glynn et al. this volume). 
The investigation of polysemous awesome presented above contributes to the discussion of the validity of an emerging fields of Cognitive Sociolinguistic. The application of this interdisciplinary perspective appears to be beneficial at a methodological and an analytical level. By employing variationist categorising methods, the multiplicity of individual conceptualisations is successfully elicited, organised, and quantified. Consequently, the analysis within a Cognitive Sociolinguistic paradigm achieves a better explanatory power of accounting for complex phenomena, which is conceptually, pragmatically, and socio-culturally grounded. This orientation in research seems to be a natural step forward in order to account for multiple functions and flexibility of meaning.

\footnotetext{
Notes:

${ }^{1}$ I would like to thank three anonymous Reviewers for their helpful comments on the earlier version of the manuscript. Author’s affiliation: University of Leeds, e-mail: j.a.robinson@ leeds.ac.uk.

${ }^{2}$ Kruskal-Wallis tests were carried out to assess whether differences in mean usage of different senses of the adjective awesome in different age groups are statistically significant. The results are as follows: awesome 'great' $\mathrm{p}<.001$, awesome 'impressive' $\mathrm{p}=.004$, awesome 'terrible' $\mathrm{p}<.000$.

${ }^{3}$ Calculations, reporting, and interpretation of statistical analyses have been carried out in consultation with Jean Russel, a chartered statistician at the University of Sheffield, whom I would like to thank for help.
}

\section{References:}

(1961). The Lancaster-Oslo/Bergen Corpus of British English. (2008). Oxford English Dictionary Online. Oxford, Oxford University Press. Bailey, G. (2002). Real and Apparent Time. The Handbook of Variation and Change. J. K. Chambers, P. Trudgill and N. Schilling-Estes. Oxford, Blackwell: 312- 332.

Beeching, K. (2005). "Politeness-induced semantic change. The case of quand même." Language Variation and Change 17: 155- 180.

Boberg, C. (2004). "Real and apparent time in language change: Late adoption of changes in Montreal English." American Speech 79(3): 250- 269.

Chambers, J. K., P. Trudgill, et al., Eds. (2002). The Handbook of Language Variation and Change. Blackwell Handbooks in Linguistics. Malden, Mass.; Oxford, Blackwell Publishers. 
Cheshire, J. (2007). "Discourse variation, grammaticalisation and stuff like that." Journal of Sociolinguistics 11(2): 155-193.

Coates, J., Ed. (1998). Language and Gender: A Reader. Oxford, Blackwell.

Coates, J. (2004). Women, Men and Language. Third Edition. London, Routledge.

Coulmas, F., Ed. (1997). The Handbook of Sociolinguistics. Oxford, Blackwell.

Dąbrowska, E. and J. Street (2006). "Individual differences in language attainment: Comprehension of passive sentences by native and non-native English speakers."

Language Sciences 28(6): 604-615.

Divjak, D. (2006). Ways of intending: delineating and structuring near synonyms. Corpora in Cognitive Linguistics: Corpus-Based Approaches to Syntax and Lexis. S. T. Gries and A. Stefanowitsch. Berlin, Mouton de Gruyter.

Eckert, P. (1997). Age as a sociolinguistic variable. The Handbook of Sociolinguistics. F. Coulmas. Oxford, Blackwell: 151-167.

Eckert, P. (1998). Gender and sociolinguistic variation. Language and Gender: A Reader. J. Coates. Oxford, Blackwell: 64-75.

Fisiak, J., Ed. (1988). Historical Dialectology : Regional and Social. Trends in Linguistics. Studies and Monographs ; 37. Mouton de Gruyter, Berlin.

Geeraerts, D. (1989). "Introduction: Prospects and problems of prototype theory." Linguistics 27: 587-612.

Geeraerts, D. (1993). Cognitive linguistics and the history of philosophical epistemology. Conceptualisations and Mental Processing in Language. R. Geiger and B. Rudzka-Ostyn. Berlin, Mouton de Gruyter: 53-79.

Geeraerts, D. (1997). Diachronic Prototype Semantics: A Contribution to Historical Lexicology. Oxford, Clarendon Press.

Geeraerts, D. (2005). Lectal variation and empirical data in Cognitive Linguistics. Cognitive Linguistics: Internal Dynamics and Interdisciplinary Interaction. F. J. R. d. M. Ibanez and M. S. P. Cervel. Berlin / New York, Mouton de Gruyter: 163-189.

Geeraerts, D. and H. Cuyckens, Eds. (2007). The Oxford Handbook of Cognitive Linguistics. Oxford, Oxford University Press. 
Geeraerts, D., S. Grondelaers, et al. (1994). The Structure of Lexical Variation. Berlin / New York, Mouton de Gruyter.

Geeraerts, D. and D. Speelman (this volume). Conceptual entrenchment and lexical uncertainty in dialects. Advances in Cognitive Sociolinguistics. D. Geeraerts, G. Kristiansen and Y. Piersman. Berlin, New York, Mouton de Gruyter.

Geiger, R. and B. Rudzka-Ostyn, Eds. (1993). Conceptualisations and Mental Processing in Language. Berlin, Mouton de Gruyter.

Glynn, D., D. Geeraerts, et al. (this volume). The semantics of extralinguistic variation. A quantitative study of dialect effects on polysemy. Advances in Cognitive Sociolinguistics. D. Geeraerts, G. Kristiansen and Y. Piersman. Berlin, New York, Mouton de Gruyter.

Gries, S. T. (2006). Corpus-based methods and cognitive semantics: The many senses of run. Corpora in Cognitive Linguistics: Corpus-Based Approaches to Syntax and Lexis. S. T. Gries and A. Stefanowitsch. Berlin, Mouton de Gruyter.

Gries, S. T. and D. Divjak (2009). Behavioural profiles: A corpus-based approach to cognitive semantic analysis New Directions in Cognitive Linguistics. V. Evans and S. S. Pourcel. Amsterdam, Benjamins: 57-75.

Gries, S. T. and A. Stefanowitsch, Eds. (2006). Corpora in Cognitive Linguistics: CorpusBased Approaches to Syntax and Lexis. Berlin, Mouton de Gruyter.

Hasan, R. (1989). "Semantic variation and sociolinguistics." Australian Journal of Linguistics 9: 221-275.

Hasan, R. (1992). Meaning in sociolinguistic theory Sociolinguistics Today: International Perspectives K. Bolton and H. Kwok. London, Routledge: 80-119.

Hasan, R., Ed. (2009). Semantic Variation: Meaning in Society and in Sociolinguistics. The Collected Works of Ruqaiya Hasan. Collected Works of Ruqaiya Hasan. London, Equinox.

Hosmer, D. W. and S. Lemeshow (1989). Applied Logistic Regression. New York, John Wiley and Sons.

Kerswill, P. (2006). Socio-economic class. The Routledge Companion to Sociolinguistics. C. Llamas and P. Stockwell. London, Routledge: 51-61.

Kleinbaum, D. (1994). Logistic Regression: A Self-earning Text. New York, SpringerVerlog. 
Kristiansen, G. and R. Dirven, Eds. (2008). Cognitive Sociolinguistics: Language Variation, Cultural Models, Social Systems. Berlin, New York, Mouton de Gruyter.

Kurath, H., Ed. (1941). Linguistic Atlas of New England. Providence, R. I., Brown University.

Labov, W. (1963). "The social motivations of a sound change." Word 19: 273- 309.

Labov, W. (1972). Sociolinguistic patterns. Philadelphia, University of Pennsylvania Press.

Labov, W. (1994). Principles of Linguistic Change. Oxford, Blackwell.

Labov, W. and L. Center for Applied (1966). The social stratification of English in New York City. [Washington], Center for Applied Linguistics.

Lakoff, G. (1987). Women, Fire, and Dangerous Things: What Categories Reveal about the Mind. Chicago, University of Chicago Press.

Llamas, C. and P. Stockwell, Eds. (2007). The Routledge Companion to Sociolinguistics. London, Routledge.

Macaulay, R. K. S. (2005). Talk that counts : age, gender, and social class differences in discourse. New York ; Oxford, Oxford University Press.

Macaulay, R. K. S. (2006). "Pure grammaticalization: The development of a teenage intensifier." Language Variation and Change 18(3): 267-283.

Moss, M., D. A. Wellman, et al. (2003). "An appraisal of multivariable logistic models in the plumonary and critical care literature." Chest 123(3): 923-928.

Nerlich, B. and D. D. Clarke (1992). "Semantic change: case studies based on traditional and cognitive semantics." Journal of Literary Semantics 21: 204- 225.

Orton, H., E. Dieth, et al., Eds. (1962- 71). Survey of English Dialects. Leeds, Arnold.

Peng, C.-Y. J., K. L. Lee, et al. (2002). "An introduction to logistic regression analysis and reporting." The Journal of Educational Research 96(1): 3-14.

Peters, H. (1988). On the state and aims of Middle English word geography. Historical Dialectology : Regional and Social. J. Fisiak. Berlin, Mouton de Gruyter: 397- 416.

Pope, J. (2002). Revisiting Martha's Vineyard. Unpublished M.A. thesis, University of Edinburgh 
Pope, J. (2002). Revisiting Martha's Vineyard. Unpublished M.A. thesis, University of Edinburgh

Poplack, S., D. Sankoff, et al. (1988). "The social correlates and linguistic processes of lexical borrowing and assimilation." Linguistics 26: 47- 104.

Roberts, K. (2001). Class in Modern Britain, Palgrave Macmillan

Romaine, S. (1994). The Language of Children and Adolescents. Oxford, Blackwell.

Rosch, E. (1975). "Cognitive representations of semantic categories." Journal of Experimental Psychology 104: 199- 233.

Ruiz de Mendoza Ibanez, F. J. and M. S. Pena Cervel, Eds. (2005). Cognitive Linguistics: Internal Dynamics and Interdisciplinary Interaction. Berlin/ New York, Mouton de Gruyter.

Sankoff, G. (2006). Apparent time and real time. Elsevier Encyclopedia of Language and Linguistics. K. Brown. Amsterdam, Elsevier. 1: 110-116.

Stenström, A.-B. (2000). It's enough funny, man: Intensifiers in teenage talk. Corpora Galore: Analyses and Techniques in Describing English. J. M. Kirk. Amsterdam, Rodopi: 177-190.

Tabachnick, B. G. and L. S. Fidell (2001). Using Multivariate Statistics. Boston, Allyn and Bacon.

Tagliamonte, S. A. and A. D'Arcy (2004). "He's like, she's like: The quotative system in Canadian youth." Journal of Sociolinguistics 8(4): 493-514.

Tagliamonte, S. A. and A. D'Arcy (2009). "Peaks beyond phonology: Adolescence, incrementation, and language change." Language 85(1): 58-108.

Trudgill, P. (1974). The social differentiation of English in Norwich. London, Cambridge University Press.

Upton, C. and J. Widdowson (1999). Lexical Erosion in English Regional Dialects. Sheffield, The University of Sheffield.

Weinreich, U., W. Labov, et al. (1968). Empirical foundations for a theory of language change Directions for Historical Linguistics: a Symposium. W. P. Lehmann and Y. Makiel. Austin, University of Texas Press: 97- 195. 
Wong, A. (2002). The Semantic Derogation of Tongzhi: A Synchronic Perspective. Language and Sexuality : Contesting Meaning in Theory and Practice. K. CampbellKibler, R. Podesva, S. J. Roberts and A. Wong. Stanford, California, CSLI: 161 - 174.

Wong, A. (2008). "On the actuation of semantic change: The case of tongzhi." Language Sciences 30(4): 423-449. 